\title{
MOTILIDADE ESPERMÁTICA E INTEGRIDADE ACROSSOMAL EM DOSES DE SÊMEN SUÍNO REFRIGERADAS E INOCULADAS COM ESCHERICHIA COLI E STAPHYLOCOCCUS AUREUS
}

\section{SPERM MOTILITY AND ACROSSOMAL INTEGRITY IN LIQUID BOAR SEMEN DOSIS INOCULATED WITH ESCHERICHIA COLI AND STAPHYLOCOCCUS AUREUS}

\author{
Paulo Eduardo Bennemann ${ }^{1}$ Fernando Pandolfo Bortolozzo ${ }^{2}$ \\ Ivo Wentz ${ }^{3}$ Marisa Ribeiro de Itapema Cardoso ${ }^{4}$
}

RESUMO

Foram utilizados 12 ejaculados, coletados de maneira asséptica, distribuídos em sete tratamentos, sendo um grupo controle e os demais inoculados com três diferentes concentrações de S. aureus ou E. coli $\left(5 \times 10^{5}, 5 \times 10^{6}\right.$ e $\left.5 \times 10^{7} \mathrm{UFC} / \mathrm{ml}\right)$. Durante 96 horas, foram avaliados a motilidade espermática, o percentual de acrossomas intactos (NAR), o pH e o número de unidades formadoras de colônia (UFC/ml) das bactérias inoculadas. $O$ desenvolvimento bacteriano foi decrescente ao longo das 96 horas de armazenamento. Com exceção do tratamento com a inoculação de $5 \times 10^{7} \mathrm{UFC}$ de $\boldsymbol{E}$. coli $/ \mathrm{ml}$, não foi observado efeito significativo das bactérias sobre a motilidade espermática ( $p>0,05)$. Da mesma forma, não houve efeito significativo $(p>0,05)$ do $\boldsymbol{S}$. aureus ou da $\boldsymbol{E}$. coli sobre o percentual de NAR $e$ pH nas 96 horas. Quando comparado ao controle, somente a inoculação de $5 \times 10^{7} \mathrm{UFC} / \mathrm{ml}$ de $\boldsymbol{E}$. coli diferiu, às 96 horas, em relação ao percentual de NAR $(p \leq 0,05)$. Não foi observada correlação entre as variáveis motilidade, NAR, pH e UFC.

Palavras-chave: sêmen, acrossoma, Escherichia coli, Staphylococcus aureus.

\section{SUMMARY}

Twelve ejaculates were collected in the most aseptic manner and distributed in seven treatments (control group T1). Semen were inoculated with $\mathbf{S}$. aureus $(T 2, T 3$ e T4) or E. coli (T5, T6 e T7) in three concentrations $\left(5 \times 10^{5}, 5 \times 10^{6}\right.$ and $5 \times 10^{7}$ $C F U / \mathrm{ml})$. The sperm motility, the percentage of normal apical range (NAR), the $\mathrm{pH}$ and the number of colony unit former (CFU/ml) of bacteria, for 96 hours, were evaluated. The bacterial development was decreasing during the first 96 hours. Except for the treatment with the inoculation of $5 \times 10^{7} \mathrm{CFU}$ of $\boldsymbol{E}$. coli $/ \mathrm{ml}$, there was no significant effect of the bacteria on the sperm motility ( $p>0.05)$. Also, there was no significant effect $(p>0.05)$ of the $\boldsymbol{S}$. aureus or $\boldsymbol{E}$. coli on the percent of NAR and the $p H$ during the 96 hours. When compared to the control group, only the inoculation of $5 \times 10^{7} \mathrm{CFU} / \mathrm{ml}$ of $\boldsymbol{E}$. coli differed at the 96 hours in relation to the percentage of NAR $(p<0.05)$. There was no correlation among the sperm motility, NAR, pH and CFU.

Key words: semen, acrosome, Escherichia coli, Staphylococcus aureus.

\section{INTRODUÇÃO}

Vários autores têm demonstrado que enterobactérias, como por exemplo a Escherichia coli (E. coli), e algumas bactérias Gram positivas, como Streptococcus sp., afetam de forma significativa a qualidade espermática, principalmente no que se refere à motilidade (RIDEOUT et al., 1982; AUROUX et al., 1991; DIEMER et al., 1996). Isso pode ocorrer pela ação de toxinas bacterianas (SONE et $\boldsymbol{a l} .$, 1982), alteração do $\mathrm{pH}$, competição pelo mesmo substrato (RIDEOUT et al., 1982) ou pela ação direta, levando a defeitos estruturais na membrana da célula espermática (DIEMER $\boldsymbol{e t} \boldsymbol{a l}$., 1996). No entanto, dados relacionados ao efeito da contaminação bacteriana sobre a integridade acrossomal são muito escassos. Segundo WOELDERS

\footnotetext{
${ }^{1}$ Mestre, Médico Veterinário, Bolsista CAPES 9090, 90540-000, Porto Alegre-RS Email: fpbortol@vortex.ufrgs.br. Autor para correspondência

${ }^{3}$ Doutor, Professor Titular, Centro de Ciências Rurais, UFSM.

${ }^{4}$ Doutor, Professor Titular, Faculdade de Veterinária, UFRGS.

${ }^{2}$ Doutor, Professor Adjunto, Faculdade de Veterinária, Universidade Federal do Rio Grande do Sul (UFRGS), Av. Bento Gonçalves, 
(1991), o acrossoma é parte fundamental nos processos de fertilização, e qualquer alteração presente pode inibir a capacidade fecundante do espermatozóide.

De acordo com DIEMER $\boldsymbol{e t}$ al. (1996) e AUROUX et al. (1991), a $\boldsymbol{E}$. coli apresenta um efeito direto sobre a motilidade progressiva da célula espermática, no entanto, esse efeito é dependente da concentração bacteriana. DEL PORTO et al. (1975) observaram que a concentração de $10^{6} \boldsymbol{E}$. coli $/ \mathrm{ml}$ de sêmen causava uma queda significativa na motilidade espermática. Contraditoriamente, EDMONDSON et al. (1948) não encontraram qualquer correlação entre o número de bactérias presentes no sêmen bovino e o período de tempo que este apresentava células móveis. No entanto, observaram que fatores de patogenicidade bacteriana, como capacidade hemolítica, estavam relacionados a uma menor manutenção da motilidade espermática.

O objetivo deste experimento foi verificar o efeito do Staphylococcus aureus e da Escherichia coli hemolítica sobre a qualidade espermática, com ênfase à motilidade espermática e integridade acrossomal.

\section{MATERIAL E MÉTODOS}

Como doadores de sêmen, foram utilizados 4 machos suínos híbridos com idades entre 11 e 13 meses, dos quais foram analisados 3 ejaculados, perfazendo um total de 12 amostras. Os animais foram submetidos a duas coletas semanais de sêmen sobre um manequim fixo. A metodologia empregada na coleta foi a técnica de estimulação mecânica do pênis, com a mão enluvada (HANCOCK \& HOVEL, 1959). Após o macho saltar sobre o manequim, foi realizada uma higienização a seco, com auxílio de papel toalha estéril, da região do óstio prepucial e, por pressão manual, o esvaziamento dos divertículos prepuciais, retirando-se o excesso de secreções acumuladas. Com a finalidade de minimizar a contaminação bacteriana do ejaculado, no momento da coleta foram desprezados os primeiros 5-10 $\mathrm{ml}$ de sêmen (COLENBRANDER $\boldsymbol{e t}$ al., 1993), sendo as frações seguintes coletadas em um copo coletor estéril, pré-aquecido a $35^{\circ} \mathrm{C}$, protegido em sua extremidade por gaze esterilizada para reter a fração gelatinosa do sêmen. O ejaculado foi obtido de tal forma que não houve contato com a luva de coleta, fluindo diretamente do meato uretral para o copo de coleta. Após a coleta, o sêmen foi encaminhado imediatamente ao laboratório para avaliação macro e microscópica, bem como para o processamento.

No laboratório, o ejaculado foi identificado e submetido a uma avaliação do peso, do aspecto, da cor e do odor. Ao exame microscópico, foram avaliados a motilidade espermática, estimada, de forma subjetiva, através do percentual de células móveis; a concentração espermática, por contagem dos espermatozóides em câmara hemocitométrica e a morfologia espermática. Uma alíquota de $100 \mu \mathrm{l}$ foi semeada em ágar-sangue para o controle da microbiota presente no sêmen in natura. As placas foram incubadas a $37^{\circ} \mathrm{C}$ por até 4 dias e avaliadas diariamente quanto ao crescimento bacteriano. $\mathrm{O}$ sêmen, após a coleta, foi mantido em banho-maria a 30$32^{\circ} \mathrm{C}$ até o momento da sua diluição. Foram diluídos os ejaculados que apresentaram no mínimo $70 \%$ de motilidade. O diluente utilizado foi o BTS (Beltsville Thawing Solution) sem a adição de antimicrobiano. Após a avaliação microscópica, cálculo da concentração espermática e do número de doses inseminantes (DI) a serem preparadas, foi procedida a diluição em uma proveta pré-aquecida a $35^{\circ} \mathrm{C}$, acrescentando-se, lentamente, o diluente ao sêmen (WENTZ \& BORTOLOZZO, 1998). Após diluído, o sêmen foi envasado em bisnagas plásticas de 100 $\mathrm{ml}$, próprias para esse fim, contendo $3 \times 10^{9}$ espermatozóides e inoculados com diferentes concentrações de $\boldsymbol{E}$. coli e $S$. aureus $\left(5 \times 10^{5} \mathrm{UFC} / \mathrm{ml}, 5 \times 10^{6}\right.$ $\mathrm{UFC} / \mathrm{ml}$ e $\left.5 \times 10^{7} \mathrm{UFC} / \mathrm{ml}\right)$. Posteriormente, as DIs foram armazenadas a $16-17^{\circ} \mathrm{C}$, durante 96 horas, sendo movimentadas 2 vezes ao dia, para ressuspensão das células espermáticas.

Para o inóculo bacteriano, foram selecionadas uma amostra de $\boldsymbol{E}$. coli e uma de $\boldsymbol{S}$. aureus, isoladas, anteriormente, de amostras de sêmen in natura de suínos (BENNEMANN, 1998). As amostras foram semeadas em caldo BHI (infuso de cérebro e coração-Difco) e crescidas a $37^{\circ} \mathrm{C}$ por 18 horas. Após a incubação, foi feita a contagem das UFC pelo método de espalhamento na superfície ágar sangue (Biobrás) acrescido de 5\% de sangue ovino. Para cada diluição, foram semeadas placas em duplicata. O cálculo das UFC/ml foi realizado a partir da contagem nas diluições que apresentavam entre 20 e 200 colônias por placa. A cultura original em BHI foi mantida entre $4-8^{\circ} \mathrm{C}$ até o cálculo do número de UFC/ml de cada cultura, sendo então, preparados os inóculos contendo aproximadamente $5 \times 10^{5}$, $5 \times 10^{6}$ e $5 \times 10^{7} \mathrm{UFC} / \mathrm{ml}$.

Cada ejaculado foi dividido, aleatoria-

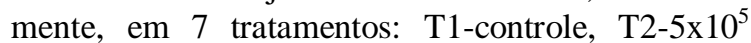

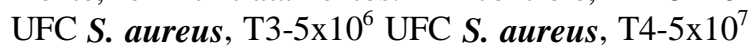

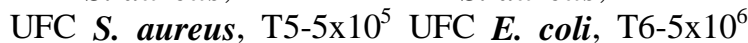

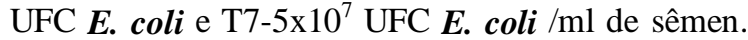
Todas as DIs foram avaliadas diariamente quanto à motilidade espermática até um período de 96 horas de armazenamento, e a cada 48 horas (hora 0,48 e 96) foi avaliada a morfologia do acrossoma 
(PURSEL \& JOHNSON, 1974) e a UFC de $\boldsymbol{E}$.coli $e$ $S$ aureus. Paralelamente ao exame morfológico, foi realizada a avaliação do $\mathrm{pH}$, utilizando-se um potenciômetro digital. Os dados foram submetidos à análise de variância utilizando o procedimento "GLM" e à análise de correlação utilizando o procedimento PROC CORR, ambos do pacote estatístico SAS (1985).

\section{RESULTADOS}

Todos os ejaculados utilizados no experimento apresentaram resultado negativo no exame bacteriológico realizado no sêmen in natura. $\mathrm{Na}$ tabela 1, é demonstrado o comportamento da $\boldsymbol{E}$. coli e do $\boldsymbol{S}$. aureus durante o período de conservação. O desenvolvimento bacteriano foi decrescente ao longo das 96 horas. Em todos os tratamentos de T2 a T7, pôde ser observada uma queda significativa do número de UFC com o passar do tempo $(\mathrm{p}<0,05)$. Nos tratamentos contendo $S$. aureus (T2 a T4), essa queda manteve um comportamento linear, enquanto nos tratamentos com $\boldsymbol{E}$. coli (T5 a T7), houve uma queda mais acentuada nas primeiras 48 horas.

$\mathrm{Na}$ tabela 2, são apresentadas as médias de motilidade espermática dos tratamentos T1 a T7 e a comparação entre os tratamentos em relação aos diferentes tempos de avaliação. As diferenças dos tratamentos T2 a T7 em relação ao T1 só foram observadas a partir das 24 horas para o T7 $(\mathrm{p}<0,05)$, e a partir das 72 horas no T4 (p=0,07), T5 e T6 ( $\mathrm{p}=$ 0,05 e 0,02 , respectivamente). O T2 e T3 não diferiram do $\mathrm{T} 1$ em nenhum momento ( $\mathrm{p}>0,05)$, embora o T1 tenha sido sempre superior, aritmeticamente, a todos os tratamentos em todos os períodos.

Tabela 1 - Médias do número de UFC/ml nos tratamentos nas horas 0, 48 e 96, após a inoculação do sêmen

\begin{tabular}{|c|c|c|c|c|}
\hline \multirow{3}{*}{ Tratamento } & \multirow{3}{*}{$\mathrm{N}$} & \multicolumn{3}{|c|}{$\mathrm{UFC} / \mathrm{ml}$ média dos tratamentos } \\
\hline & & \multicolumn{3}{|c|}{ Tempo (horas) } \\
\hline & & 0 & 48 & 96 \\
\hline $\mathrm{T} 1$ & 12 & $0,00^{\mathrm{Aa}}$ & $0,00^{\mathrm{Aa}}$ & $0,00^{\mathrm{Aa}}$ \\
\hline $\mathrm{T} 2$ & 12 & $33,75^{\mathrm{Aa}}$ & $19,58^{\mathrm{Aa}}$ & $9,58^{\mathrm{Aa}}$ \\
\hline T3 & 12 & $280,83^{\text {В а }}$ & $160,42^{\mathrm{A} \mathrm{B} \mathrm{ac}}$ & $85,42^{\mathrm{Abc}}$ \\
\hline $\mathrm{T} 4$ & 12 & $2.500,83^{\mathrm{Ca}}$ & $1.622,50^{\mathrm{Db}}$ & $890,83^{\mathrm{B} \mathrm{c}}$ \\
\hline T5 & 12 & $53,75^{\mathrm{A} \mathrm{a}}$ & $3,33^{\mathrm{Aa}}$ & $0,00^{\mathrm{A} \mathrm{a}}$ \\
\hline T6 & 12 & $545,00^{\mathrm{Da}}$ & $47,50^{\mathrm{ACb}}$ & $12,92^{\mathrm{Ab}}$ \\
\hline $\mathrm{T} 7$ & 12 & $2.441,11^{\mathrm{Ca}}$ & $211,25^{\text {В C b }}$ & $36,25^{\mathrm{Ac}}$ \\
\hline
\end{tabular}

A, B, C, D na coluna diferem para $\mathrm{p} \leq 0,05$.

$\mathrm{a}, \mathrm{b}, \mathrm{c}$ na linha diferem para $\mathrm{p} \leq 0,05$.
A motilidade espermática foi influenciada pelo tipo de bactéria inoculada $(\mathrm{p}<0,01)$. Os tratamentos inoculados com $\boldsymbol{S}$. aureus (T2, T3 e T4) apresentaram uma maior motilidade espermática em relação aos tratamentos inoculados com $\boldsymbol{E}$. coli (T5, T6 e T7), 78,19 $\pm 1,65$ e 73,19 $\pm 1,26$, respectivamente $(\mathrm{p}<0,01)$. Da mesma forma que o tipo de bactéria, a concentração dessas mostrou um efeito negativo sobre a motilidade média observada nas 96 horas de armazenamento. Ao se comparar a motilidade nas diferentes concentrações, avaliando as duas bactérias inoculadas, observa-se que o efeito foi mais marcante nos tratamentos T4 e T7 ( $\mathrm{p}=0,03)$, onde havia sido inoculado $5 \times 10^{7} \mathrm{UFC} / \mathrm{ml}$ de sêmen. Já nos tratamentos T2 e T5, e T3 e T6, onde o número de $\mathrm{UFC} / \mathrm{ml}$ inoculadas foi menor $\left(5 \times 10^{5}\right.$ e $5 \times 10^{6}$ $\mathrm{UFC} / \mathrm{ml}$ de sêmen, respectivamente), não foi observado um efeito significativo sobre a motilidade espermática $(\mathrm{p}=0,08 \mathrm{e} \mathrm{p}=0,13$, respectivamente).

A integridade de acrossoma não foi afetada pelo tipo de bactéria inoculada (S. aureus ou $\boldsymbol{E}$. coli), ao longo do tempo $(\mathrm{p}=0,23)$. Na tabela 3 , são apresentadas as médias do percentual de NAR (acrossomas intactos) em cada tratamento até às 96 horas de avaliação. Durante esse período, não houve diferença no percentual de NAR entre os tratamentos T2 a T6 em relação ao T1 (p>0,05). Somente o T7 apresentou diferença significativa às 96 horas em relação ao $\mathrm{T} 1(\mathrm{p}=0,02)$. Se for considerado um nível mínimo de significância de $10 \%$, o T7 difere de todos os demais tratamentos na hora 96.

$\mathrm{O}$ pH apresentou um comportamento decrescente ao longo do tempo. Na hora 0 , em todos os tratamentos, o valor foi 7,49 $\pm 0,02$, passando, em média, a 7,42 $\pm 0,14$ nas primeiras 48 horas e, a $7,35 \pm 0,02$ na hora 96 . No T1, foi observada uma queda significativa de $\mathrm{pH}$ nas primeiras 48 horas $(\mathrm{p}=0,05)$, o que só foi evidenciado nos outros tratamentos após esse período $(\mathrm{p}<0,01)$. Não foi observado efeito do inóculo sobre o valor de $\mathrm{pH}(\mathrm{p}=0,71)$.

$\mathrm{Na}$ análise de correlações entre as variáveis motilidade espermática, percentual de NAR, $\mathrm{pH}$ e UFC/ml, foi observada a existência de uma correlação de grau médio $(r=0,48)$, positiva e significativa entre o percentual médio de espermatozóides móveis e o percentual médio de NAR. A correlação entre o percentual médio de espermatozóides móveis e o número médio de $\mathrm{UFC} / \mathrm{ml}$ foi negativa e significativa $(p=0,01)$, embora tenha sido fraca $(r=-0,15)$. Já a correlação entre o percentual médio de espermatozóides móveis e o valor do $\mathrm{pH}$ foi negativa, fraca $(\mathrm{p}=0,21)$. A análise de correlação entre percentual de acrossomas normais e número de UFC/ml foi praticamente nula $(\mathrm{r}=-0,06)$, negativa e não significativa. Quando o percentual de NAR foi correlaci- 
Tabela 2 - Motilidade espermática média dos tratamentos T1 a T7 nas horas 0, 24, 48, 72 e 96, após a inoculação do sêmen.

\begin{tabular}{|c|c|c|c|c|c|c|}
\hline \multirow{3}{*}{ Tratamento } & \multirow{3}{*}{$\mathrm{n}$} & \multicolumn{5}{|c|}{ Motilidade média dos tratamentos (\%) } \\
\hline & & \multicolumn{5}{|c|}{ Tempo (horas) } \\
\hline & & 0 & 24 & 48 & 72 & 96 \\
\hline $\mathrm{T} 1$ & 12 & $92,08^{\mathrm{Aa}}$ & $84,58^{\mathrm{Aab}}$ & $81,25^{\mathrm{Ab}}$ & $75,42^{\mathrm{Abc}}$ & $68,33^{\mathrm{Ac}}$ \\
\hline $\mathrm{T} 2$ & 12 & $92,08^{\mathrm{Aa}}$ & $84,17^{\mathrm{Aab}}$ & $81,25^{\mathrm{Abc}}$ & $74,17^{\mathrm{ACcd}}$ & $67,08^{\mathrm{Ad}}$ \\
\hline $\mathrm{T} 3$ & 12 & $92,08^{\mathrm{Aa}}$ & $84,58^{\mathrm{Aab}}$ & $81,67^{\mathrm{Ab}}$ & $71,25^{\mathrm{AB} \mathrm{c}}$ & $67,08^{\mathrm{Ac}}$ \\
\hline $\mathrm{T} 4$ & 12 & $92,08^{\text {A a }}$ & 80,41 А В в & $74,58^{\text {А B b c }}$ & $66,67^{\mathrm{AB} \mathrm{c} \mathrm{d}}$ & $63,75^{\mathrm{Ad}}$ \\
\hline T5 & 12 & $92,08^{\mathrm{Aa}}$ & $81,67^{\mathrm{Ab}}$ & $79,58^{\mathrm{Ab}}$ & $65,83^{\mathrm{B} \mathrm{Cc}}$ & $62,17^{\mathrm{AB} \mathrm{c}}$ \\
\hline T6 & 12 & $92,08^{\mathrm{Aa}}$ & $82,03^{\mathrm{Ab}}$ & 77,91 А В в & $64,16^{\mathrm{Bd}}$ & $60,00^{\mathrm{AB} \mathrm{d}}$ \\
\hline $\mathrm{T} 7$ & 12 & $92,08^{\mathrm{Aa}}$ & $72,91^{\mathrm{B} \mathrm{b}}$ & $70,42^{\mathrm{B} \mathrm{bc}}$ & $62,92^{\mathrm{Bc}}$ & $53,33^{\mathrm{Bd}}$ \\
\hline
\end{tabular}

$\mathrm{A}, \mathrm{B}, \mathrm{C}$ na coluna diferem para $\mathrm{p} \leq 0,05$.

$\mathrm{a}, \mathrm{b}, \mathrm{c}, \mathrm{d}$ na linha diferem para $\mathrm{p} \leq 0,05$.

onado com o valor do $\mathrm{pH}$, demonstrou uma correlação fraca $(\mathrm{r}=-0,23)$, negativa e signicativa. Já o valor de $\mathrm{pH}$ e número de $\mathrm{UFC} / \mathrm{ml}$ demonstrou uma correlação fraca $(r=-0,10)$, negativa e não significativa.

\section{DISCUSSÃO}

DIEMER $\boldsymbol{e t}$ al. (1996), RIDEOUT $\boldsymbol{e t}$ al. (1982) e EDMONDSON et al. (1948) demonstraram que, bactérias como $\boldsymbol{E}$. coli, e algumas bactérias hemolíticas, Gram negativas ou positivas, afetavam de forma significativa a qualidade espermática, principalmente no que se refere à motilidade. Dados relacionados ao efeito de bactérias e sua concentração sobre a integridade acrossomal são pouco pesquisados.

Tabela 3 - Média do percentual de acrossomas intactos (NAR) dos tratamentos na hora 0,48 , e 96 , após a inoculação do sêmen.

\begin{tabular}{ccccc}
\hline & \multicolumn{5}{c}{ NAR médio dos tratamentos $(\%)$} \\
Tratamento & $\mathrm{N}$ & 0 & $\begin{array}{c}\text { Tempo (horas) } \\
48\end{array}$ \\
& \multicolumn{5}{c}{96} \\
T1 & 12 & $99,50^{\mathrm{Aa}}$ & $83,91^{\mathrm{Ab}}$ & $82,25^{\mathrm{Ab}}$ \\
T2 & 12 & $99,50^{\mathrm{Aa}}$ & $83,95^{\mathrm{Ab}}$ & $80,29^{\mathrm{AB} \mathrm{b}}$ \\
T3 & 12 & $99,50^{\mathrm{Aa}}$ & $87,62^{\mathrm{AB} \mathrm{b}}$ & $83,37^{\mathrm{AB} \mathrm{b}}$ \\
T4 & 12 & $99,50^{\mathrm{Aa}}$ & $81,04^{\mathrm{ACb}}$ & $80,08^{\mathrm{AB} \mathrm{b}}$ \\
T5 & 12 & $99,50^{\mathrm{Aa}}$ & $83,17^{\mathrm{Ab}}$ & $81,12^{\mathrm{AB} \mathrm{b}}$ \\
T6 & 12 & $99,50^{\mathrm{Aa}}$ & $84,00^{\mathrm{Ab}}$ & $81,29^{\mathrm{AB} \mathrm{b}}$ \\
T7 & 12 & $99,50^{\mathrm{Aa}}$ & $81,04^{\mathrm{ACb}}$ & $74,46^{\mathrm{B} \mathrm{b}}$ \\
& & & \\
\hline
\end{tabular}

$\mathrm{A}, \mathrm{B}, \mathrm{C}$ na coluna diferem para $\mathrm{p} \leq 0,05$.

$\mathrm{a}, \mathrm{b}$ na linha diferem para $\mathrm{p} \leq 0,05$.
Neste experimento, contraditoriamente ao observado por BENNEMANN (1998), que trabalhou com bactérias isoladas do sêmen suíno diluído, o crescimento foi decrescente ao longo do tempo. Segundo CHANSILPA (1987), esse fato poderia estar relacionado à mudança das bactérias para um meio diferente, o que dificultaria a adaptação e o desenvolvimento das mesmas. Assim, é possível que as bactérias retiradas de um meio rico (BHI) e inoculadas em um meio pobre, no caso o diluente de sêmen BTS, tendo a glicose como principal nutriente, tivessem dificuldades para se adaptar e crescer. No trabalho de BENNEMANN (1998), as bactérias já estavam adaptadas às condições de restrição nutricional no divertículo prepucial e no meio ambiente, não apresentando problemas de adaptação ao serem transferidas para o diluente. Outra hipótese para o declínio do crescimento bacteriano seria um possível efeito antimicrobiano do plasma seminal sobre algumas bactérias. SCHOLLUM et al. (1977), avaliando o efeito do plasma seminal bovino e humano sobre diferentes bactérias Gram positivas e negativas, observaram que $17 \%$ das bactérias Gram positivas e $18 \%$ das Gram negativas testadas eram sensíveis à ação do plasma seminal bovino e que, quando essas mesmas bactérias foram submetidas ao plasma seminal humano, este número passava a $40 \%$ e $47 \%$, respectivamente. A atividade antimicrobiana do sêmen tem sido atribuída a alguns componentes do plasma seminal, como a espermina, a espermidina e a lisozima (SCHOLLUM et al., 1977). Entretanto, a espermina só está presente em altas concentrações $(50-350 \mathrm{mg} / \mathrm{ml})$ no sêmen humano, sendo que nos animais domésticos é aparentemente ausente (STABENFELDT \& EDQVIST, 1988). SCHOLLUM et al. (1977) também demonstraram que, no bovino, esse efeito não estava ligado à espermina ou à lisozima, mas a determinadas proteínas termo-estáveis ainda desconhecidas. Os autores demonstraram que bactérias como $\boldsymbol{S}$. aureus e $\boldsymbol{E}$. coli apresentavam sensibilidade ao plasma seminal. No entanto, bactérias como Proteus sp., Pseudomonas sp., Streptococcus e alguns Staphylococcus sp., que foram as bactérias sempre presentes nas DIs do experimento de BENNEMANN (1998), apresentaram resistência. Ao mesmo tempo, no experimento de BENNEMANN (1998) havia a interação de diferentes bactérias, o que pode ter mascarado um possí- 
vel efeito do plasma seminal que, eventualmente, tenha se manifestado no presente experimento, onde as contaminações das doses inseminantes foram realizadas com culturas puras. Especula-se que o plasma seminal suíno possua um efeito antimicrobiano semelhante ao bovino, entretanto há a necessidade de se comprovar tal teoria.

No que se refere à motilidade espermática, com exceção do T7, foi semelhante entre os tratamentos. Houve um efeito significativo do tipo de bactéria inoculada sobre a motilidade espermática ( $\mathrm{p}=0,01)$. As DIs inoculadas com $\boldsymbol{E}$. coli (T5 a T7), apresentaram uma menor motilidade em relação àquelas inoculadas com $\boldsymbol{S}$. aureus (T2 a T4). Segundo DIEMER et al. (1996) e AUROUX et al. (1991), a $\boldsymbol{E}$. coli é capaz de afetar, de forma negativa, a motilidade, sendo esse efeito, provavelmente, devido a aderências da bactéria à membrana plasmática do espermatozóide, levando a defeitos estruturais do mesmo que, possivelmente, estariam relacionados a menor motilidade da célula espermática.

A queda de motilidade foi observada, principalmente, no T7 (5 x $\left.10^{7} \mathrm{UFC} / \mathrm{ml}\right)$. Por outro lado, a concentração de $5 \times 10^{6} \boldsymbol{E}$. coli $/ \mathrm{ml}$ não afetou de forma significativa a motilidade espermática média se comparada ao tratamento controle. Esse dado é contraditório ao de DEL PORTO (1975) que observou que concentrações de $\boldsymbol{E}$. Coli, a partir de $10^{6}$ bactérias $/ \mathrm{ml}$, afetavam de forma significativa ( $\mathrm{p}$ $<0,05)$ a motilidade espermática. Só foi observada diferença do T6 em relação ao T1 às 72 horas $(\mathrm{p}=$ $0,02)$. No entanto, às 96 horas essa diferença já não foi mais observada.

A integridade acrossomal, por sua vez, não foi influenciada pelo tipo de bactéria inoculada. Apenas o T7, às 96 horas, apresentou diferença significativa em relação ao T1 $(\mathrm{p}=0,01)$. Entretanto, entre os tratamentos T2 a T7, não foi observada qualquer diferença significativa ao longo das 96 horas ( $p>0,05)$. Como DIEMER et al. (1996) observaram defeitos estruturais à membrana do espermatozóide, causados por $\boldsymbol{E}$. coli, era esperado um maior percentual de acrossomas danificados.

Durante o período de armazenamento, o pH não foi influenciado pela presença da $\boldsymbol{E}$. coli e do S. aureus nas diferentes concentrações. Os valores de $\mathrm{pH}$, em todos os tratamentos, oscilaram entre 7,39 na hora 0 e 7,38 a 7,34 na hora 8. RIDEOUT et al. (1982), em experimento com filtrados bacterianos e sua ação sobre a motilidade espermática, observaram que, a $\boldsymbol{E}$. coli foi a bactéria que apresentou o $\mathrm{pH}$ mais alcalino, situando-se entre 7,10 a 7,15. Apesar de não haver diferença entre os tratamentos, houve uma acidificação do pH em relação ao valor inicial. Essa acidificação pode ser atribuída à ação bacteria- na ou ao metabolismo espermático, através da produção e acúmulo de ácido lático (SHELBY \& FOLEY, 1966), uma vez que não houve diferença dos tratamentos em relação ao T1. O fato do diluente utilizado (BTS) conter um tampão, mesmo que fraco, possivelmente contribuiu para ocorrer apenas uma pequena variação do $\mathrm{pH}$ entre os tratamentos.

A correlação entre $\mathrm{pH}$ e motilidade foi praticamente nula $(\mathrm{r}=-0,08)$, ou seja, o valor do $\mathrm{pH}$ não influenciou, negativamente, a motilidade espermática. Segundo MUEHLEIS \& LONG (1976), variações de pH entre 6,7 e 9,8 não causam efeito negativo significativo sobre a motilidade espermática. Entretanto, oscilações acima de 9,8, são capazes de reduzir a motilidade espermática, porém, menos do que em condições ácidas.

\section{CONCLUSÕES}

Nas condições em que foi desenvolvido este experimento, pode-se concluir que há uma redução significativa do número de bactérias inoculadas ao longo das 96 horas de armazenamento das doses de sêmen. Somente a $\boldsymbol{E}$. coli, na concentração de $5 \times 10^{7} \mathrm{UFC} / \mathrm{ml}$ de sêmen, afeta de forma significativa, a motilidade espermática, em relação ao controle. O percentual de NAR não é afetado pelo tipo e concentração bacteriana até às 48 horas de armazenamento. No entanto, após às 48 horas, a $\boldsymbol{E}$. coli, na concentração de $5 \times 10^{7} \mathrm{UFC} / \mathrm{ml}$, afeta de forma significativa o percentual de NAR.

\section{REFERÊNCIAS BIBLIOGRÁFICAS}

AUROUX, M.R., JACQUES, L., MATHIEU, D., $\boldsymbol{e}$ t $\boldsymbol{a l}$. Is the sperm bacterial ratio a determining factor in impairment of sperm motility: na in-vitro study in man with Escherichia coli. International Journal of Andrology, v.14, n.4, p.264270, 1991.

BENNEMANN, P.E. Avaliação de doses inseminantes produzidas em centrais de inseminação artificial de suínos no sul do Brasil e o efeito da contaminação bacteriana sobre a qualidade espermática. Porto Alegre, 1998. 254p. Dissertação (Mestrado em Ciências Veterinárias) - Curso de Pós-graduação em Ciências Veterinárias, Universidade Federal do Rio Grande do Sul, 1998.

CHANSILPA, T. Die Bedeutung von Keimgehalt und Antibiotikazusatz für die Haltbarkeit von chweinefrischsperma bei $+\mathbf{1 5}^{\mathbf{}} \mathbf{C}$. Hannover, 1987. 99p. Tese (Doctor Medicinae Veterinariae) - Tierärztliche Hochschule Hannover, 1987.

COLENBRANDER, B., FEITSMA, H., GROOTEN, H.J. Optimizing semen production for artificial insemination in swine. Journal of Reproduction and Fertility, Suppl.48. p.207-215, 1993. 
PORTO, G.B. Del, DERRICK, F.C.Jr, BANNISTER, E.R. Bacterial effect on sperm motility. Urology, v.5, n.5, p.638639, 1975.

DIEMER, T., WEIDNER, W., MICHELMANN, H.W., et al. Influence of Escherichia coli on motility parameters of human spermatozoa in vitro. International Journal of Andrology, v.19, n.5, p.271-277, 1996.

EDMONDSON, J.E., TALLMAN, K.L., HERMAN, H.A. Study of the types of bacterial in bovine semen and their effect upon motility. Journal of Dairy Science, v.31, p.681, 1948.

HANCOCK, J.L., HOWELL, G.J.R. The collection of boar semen. Veterinary Record, v.71, p.664-665, 1959.

MUEHLEIS, P.M., LONG, S.Y. The effects of altering the $\mathrm{pH}$ of seminal fluid on the sex ratio of rabbit offspring. Fertility and Sterility, v.27, n.12, p.1438-1445, 1976

PURSEL, V.G., JOHNSON, L.A. Glutaraldehyde fixation of boar spermatozoa for acrossome evaluation. Theriogenology, v.1, n.2, p.63-68, 1974

RIDEOUT, M.I., BURNS, S.J., SIMPSON, R.B. Influence of bacterial pruducts on the motility of stallion spermatozoa Journal of Reproduction and Fertility, Suppl.32. p.35-40, 1982
SAS users Guide: Statistics, version 5. ed. North Carolina. USA: SAS Institute1985. p.956.

SCHOLLUM, L.M., JARVIS, B.D.W., BACON, D.F. Antimicrobial activity of bovine seminal plasma. New Zealand Journal of Agricultural Research, v.20, p.283-290, 1977

SHELBY, D.R., FOLEY, C.W. Influence of carbon dioxide absorbent on the consumption of oxigen by boar spermatozoa. Journal of Animal Science, v.25, p.352-354, 1966.

SONE, M., OHMURA, K., BAMBA, K. Effects of various antibiotics on the control of bacterial in boar semen. Veterinary Record, n.111, p.11-14, 1982.

STABENFELDT, G.H., EDQVIST, L.E. Processos reprodutivos no macho. In: SWENSON, M.J. Dukes fisiologia dos animais domésticos. Rio de Janeiro : Guanabara, 1988. p.719-730.

WENTZ, Ivo, BORTOLOZZO, F.P. Inseminação Artificial em Suínos. In: SOBESTIANSKY, J.; WENTZ, IVO SILVEIRA, P.R.S.; SESTI, L.A.C. Suinocultura intensiva: produção, manejo e saúde do rebanho. Concórdia : EMBRAPA-CNPSA, 1998. p.388.

WOELDERS, H. Overview of in methods for evaluation of semen quality. Reproduction in Domestic Animals, Suppl.1, p.145-164, 1991.

Ciência Rural, v. 30, n. 2, 2000. 